Florida International University FIU Digital Commons

7-28-1999

\title{
The sexual division of labor : the impact of organizational change upon group cohesion and the creation of occupational identity
}

Robert M. Bossarte

Florida International University

DOI: $10.25148 /$ etd.FI14051803

Follow this and additional works at: https:// digitalcommons.fiu.edu/etd

Part of the Quantitative, Qualitative, Comparative, and Historical Methodologies Commons

\section{Recommended Citation}

Bossarte, Robert M., "The sexual division of labor : the impact of organizational change upon group cohesion and the creation of occupational identity" (1999). FIU Electronic Theses and Dissertations. 1773.

https://digitalcommons.fiu.edu/etd/1773 
Miami, Florida

THE SEXUAL DIVISION OF LABOR: THE IMPACT OF ORGANIZATIONAL CHANGE UPON GROUP COHESION AND THE CREATION OF OCCUPATIONAL IDENTITY

A thesis submitted in partial fulfillment of the requirements for the degree of

MASTER OF ARTS

in

COMPARITIVE SOCIOLOGY

by

Robert M. Bossarte 
To: Dean Arthur W. Herriot

College of Arts and Sciences

This thesis, written by Robert M. Bossarte, and entitled The Sexual Division of Labor: The Impact of Organizational Change upon Group Cohesion and the Creation of Occupational Identity, having been approved in respect to style and intellectual content, is referred to you for judgment.

We have read this thesis and recommend that it be approved.

Lois West, Ph.D.

Hugh Gladwin, Ph.D.

Stephen Fjellman, Ph.D., Major Professor

Date of Defense: July 28, 1999

The thesis of Robert M. Bossarte is approved.

Florida International University, 1999 
(C) Copyright 1999 by Robert M. Bossarte

All rights reserved. 


\section{DEDICATION}

I dedicate this thesis to my wife Tara. Without her patience and understanding, I could never follow my dreams. 


\section{ACKNOWLEDGMENTS}

I wish to thank the members of my committee for their guidance, patience, and participation. Additionally, I would like to thank the firefighters, paramedics, and administrative personnel that volunteered their time and attention to this study. Without their insight, this research would not have been possible.

Lastly, I would like to thank Lt. Mike McJury, FF Jim Schmidt, FM Steve Driscoll, Lt. John Sherry, and the all of the firefighters and Chiefs of Battalion Two who made the completion of this project a reality. This truly was a group project. 


\title{
THE SEXUAL DIVISION OF LABOR: THE IMPACT OF ORGANIZATIONAL CHANGE UPON GROUP COHESION AND THE CREATION OF OCCUPATIONAL IDENTITY
}

by

\author{
Robert M. Bossarte \\ Florida International University, 1999 \\ Miami, Florida \\ Professor Stephen Fjellman, Major Professor
}

The purpose of this research is to identify the impact of recent organizational change upon the culture of firefighting.

The experiences of female firefighters were utilized as a measure of cultural change. A purposive sample of twenty-seven male and female firefighters were interviewed in a semi-structured format about their experiences in the fire service.

This research found that the culture of firefighting has adjusted to the presence of previously excluded groups by forging a division among the identities and roles of male and female firefighters. The white, male firefighters, who have traditionally constituted a majority of the workforce, have continued to identify with traditional firefighter roles and reported high levels of cohesion. In contrast, the female firefighters showed a greater variance in their identification with traditional roles and decreased levels of cohesion with the main body of the group. 


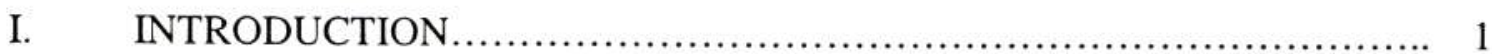

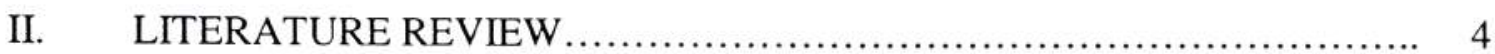

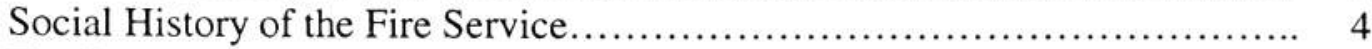

Firefighting as a Culture ............................................... 7

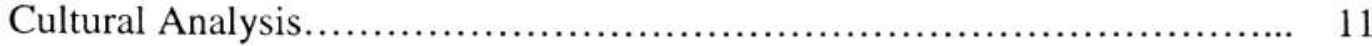

Organizational Considerations.......................................... 13

Women Working in a Man's World.................................... 20

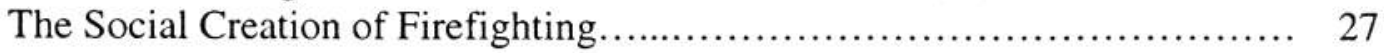

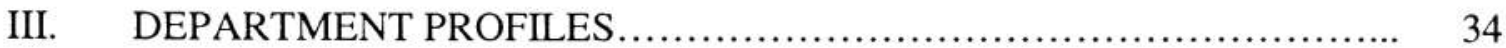

IV. RESEARCH METHODOLGY ..................................... 36

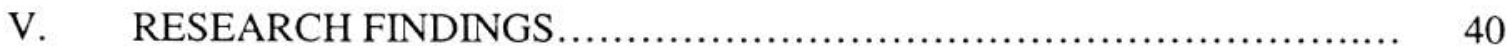

Division Among Women............................................... 40

Working Among Men .............................................. 41

The Sexual Division of Labor.......................................... 46

Gender and the Construction of Occupational Identity.................... 47

Gender and Group Cohesion......................................... 48

Structural Change, Cultural Transformation, and Group Cohesion........... 49

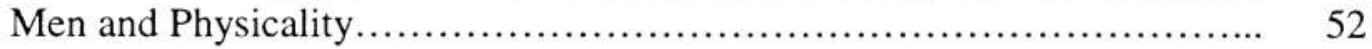

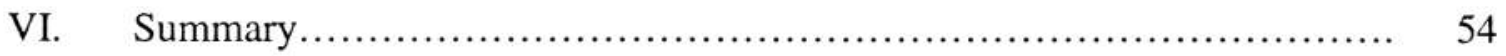

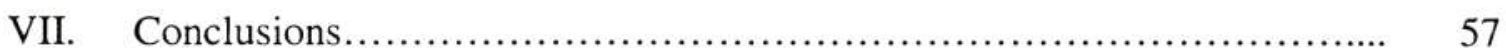

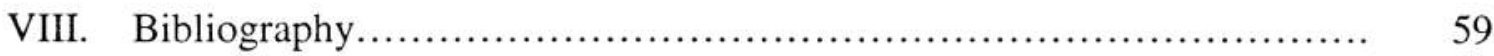

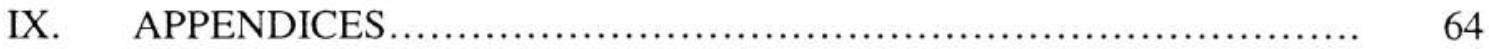




\section{INTRODUCTION}

The Fire Service is a place where masculinity is revered. In the firefighter's world the lines separating social categories are natural, clear, and point to a time when things are perceived as having been simpler. In this world men are portrayed as warriors, battling against nature and death in a heroic effort to protect those who call upon them. In contrast, women, children and "regular" men are seen as potential victims who must be protected and rescued.

However, the world of the firefighter is also one of exclusion. Along with its long history of custom and community, the fire service has traditionally relied upon the exclusion of minority and female members as a means of maintaining high levels of group homogeneity. Commonly referred to as the "Good Old Boy" system, recruits were often picked based less upon individual ability than upon social classification. The Fire Service was the domain of the white, working-class male. As such recruits seldom varied from this singular class and new members were often solicited by the Chief himself and hand-picked according to their military background or their relation to somebody already working within the department.

While this style of recruitment was effective in maintaining high levels of homogeneity, it was not responsive to the changing social and political climate of the late twentieth century. With the enactment of equal access legislation and affirmative action programs, the fire service has been forced to open its ranks to a variety of applicants. Those groups that had once constituted the "victims" were now joining the ranks of the fire service and serving alongside individuals that had been initiated into a very different 
working environment. The integration of the Fire Service had revealed the group specific nature of the norms and labels that had been utilized by the traditional firefighting culture.

This research will explore the affects of the integration of various minority groups into the ranks of the fire service. Specifically, I intend to focus upon the impact that this move toward equal access has had upon the community and culture of firefighting. My hypothesis in undertaking this endeavor is that the group specific norms, values, and rituals, upon which the culture of firefighting is established, preclude the full assimilation of women into the community of firefighting.

As the Fire Service is continually moved into the world of equal opportunity employment, the very values and roles that once defined the fire service have been replaced with a more "business-like" organizational structure. In turn, this shift in organizational structure has moved the center of social control away from the working firefighter, has lessened the specificity of group values and rituals, and has signaled a change in the firefighting community.

As a measure of this transition in culture and community, I will expiore the role of women in the fire service. The investigation of the assimilation of female firefighters into the Fire Service provides for a specific measure of the impact that organizational change has had upon the foundations of a male dominated working environment.

The unique nature of the fire service offers a variety of research opportunities. Its highly masculine nature creates an optimal situation to explore concepts of masculinity and the creation of masculine ideals. The introduction of women into a strongly gendered working environment allows for the exploration of a variety of issues relating to the 
transformation of gender specific, occupationally-based identities and the interplay of male and female power differentials.

Ultimately, however, this research is focused upon an analysis of cultural change. It is my proposal that the strength of the culture of firefighting (measured in the group's ability to enforce norms, pass along rituals, and maintain a consistent belief system) has created a unique cultural community. Community, as defined by Gallagher \& Padfield (1980), is a "social unit existing for a purpose in a particular place." (1) Historically, that social unit has been largely comprised of white males and, as I will later argue, has existed for both maintaining and recreating social expressions of masculinity.

Based upon American cultural values and widely supported by the social and political institutions, the American firefighting culture had remained relatively unchanged throughout most of its existence.

However, following the introduction of women into the Fire Service in the mid1970s, fire administrators began to initiate policy changes that would limit the potential for negative repercussions facing the new female recruits. Unfortunately, the efforts to introduce formerly excluded members into the Fire Service were hampered by the strength of the male-based identity that had been a cornerstone of firefighting culture. Hypothetically, the resulting lag between structural change and cultural expression can be measured in terms of the acceptance of women in the firehouse.

This research is more than merely an attempt to detail the change of a groupspecific cultural system. It is an exploratory study designed to investigate into the strength of gendered identities, the potential impact of decreased group cohesion upon organizational function and the social and occupational construction of identity. The 
research questions addressed by this research include; does a firefighting culture exist?

How has the introduction of women into the Fire Service affected the culture of firefighting? What is the relationship between the culture of firefighting and the social construction of masculinity? Lastly, how have women been able to assimilate into firefighting culture?

\section{LITERATURE REVIEW}

\section{The Social History of the Fire Service}

America's fascination with the fire service can be traced back to November 14, 1647 (Holzman, 1956), when the Dutch Governor Peter Stuyvesant requested from his advisors a list of suggestions that would help to protect communities from the destruction of fire.

Following a period of construction renovations and legislative changes, the first organized American fire system was born in New Amsterdam in 1658 (Greenberg, 1998). Other communities with large populations would soon follow and shortly after fires destroyed much of their communities, both Boston and Philadelphia would form organized fire fighting contingencies.

The first American fire brigades were limited strictly to members of the upper class and wealthy landowners (Zurier, 1982) who banded together to protect their investments. Bonded by similar interests and values, these early firefighting organizations began to take on a distinct social quality.

Removed from the duties of the fire brigade, the members of these early companies would often meet at local taverns for an evening's entertainment 
(Holzman,1956). These two developments, the involvement of the elite in firefighting activities, and the importance of social networking among fire companies, were critical developments in the birth of the American firefighting culture.

When the private fire brigades were replaced with paid, professional departments and opened to all (male) citizens in 1850-1860 (Holzman, 1956) the involvement of all classes of men transcended all previous social barriers. Rich or poor, landowner or renter, all barriers between the classes were removed as the firefighters worked in unison to "protect" the public.

Once he was wearing his red shirt and black helmet, the volunteer fireman knew no peers. Here (as almost nowhere else) was real democracy. The bookkeeper grappled a towrope next to the banker and at the firehouse socials, anyone could introduce his wife to the alderman. There was the leavening influence of common danger. There was a wonderful esprit de corps. (Holzman, 27)

This combination of community citizen and public servant combined to produce an idealization of the fire fighter as a "noble" activity. Transcending economic interest and forgoing the usual social divisions between the classes (Zurier, 1982), the fire brigade served as an exemplary model of "American Democracy."

With the fire brigade's position in the American colonial landscape, it is reasonable that for many members of the local brigades, identification as a "firefighter" surpassed all other social classifications. Objects of fascination for both print and song (Greenberg, 1998), the firefighter was heralded as the embodiment of the American spirit. Therefore, while the purely voluntary basis of the early brigades limited any true economic reward, the social capital (Bourdieu, 1979) gained through their association 
with firefighting was great enough to become the volunteer fire fighter's central social manifestation.

Central to the firefighter's social identity was the relationship between firefighting and masculinity. Seen not simply as public servants, but as warriors in battle (Greenberg, 1997) the firefighter became the an epitomized embodiment of the American "man." Drawing upon American idealizations of rugged individuality and the social expression of gender, the world of firefighting became the sole domain of men.

It should be mentioned, however, that the effective transmission of culturally relevant values, such as those discussed in the preceding paragraphs, and the maintenance of high levels of groups cohesion are dependent upon the overwhelming homogeneity of the group. As has been identified in previous organizational studies of the fire department (Cargill, 1996), group cohesiveness can be adversely affected by the introduction of outgroup members that do not share a common value base.

By looking back into history at the social and political landscape surrounding the formation of the earliest fire brigades, it is possible to identify four characteristics that define the orientation of the "traditional" fire service. (1) A primary identification among the members of the fire service as "firefighter" transcending other roles. (2) A masculinization of the fire service based upon socially constructed classifications and historically gendered behavior expectations. (3) An idealization of the fire fighter as an embodiment of American values, and (4) a lack of recognition of class based differences between individual firefighters.

While the introduction of previously excluded groups has changed the face of the modern firefighting culture, the fire department's place in the American community is as 
strong as ever. According to data collected by the United States Fire Administration (1997), there are currently more than one million fire fighters $(275,700$ paid $\& 803,350$ volunteer) working within 30,665 different fire departments throughout the country. In response to the massive urbanization of the early twentieth century, the major metropolitan areas began replacing their volunteer fire brigades with more tightly controlled professional (paid) fire departments. Today $59 \%$ of the U.S. population is protected by the $11 \%$ of fire departments that are either completely, or predominantly career oriented. (FEMA, 1997) The remaining $41 \%$ of the population is served by volunteer fire departments that still rely upon the participation of local residents. Like other government agencies, the modern professional fire department offers its employees lucrative salaries, health insurance, and retirement benefits. Based upon the limited number of qualifications needed for entry (Florida requires only a high school diploma or its equivalent) and the short duration of the schooling (currently 10 weeks full-time) access to fire department jobs has become quite competitive.

\section{Fire Fighting as a Culture}

Central to the argument of this thesis is the recognition of firefighting as a unique and reproducing culture. As such, it is necessary to develop both a working definition of culture, as it relates to this body of work, and an understanding of the norms and values central to the culture of firefighting.

In attempting to arrive at a working definition of "culture" for this research, I have had to consider the wide range of definitions offered by the existing literature. Additionally problematic in the adaptation of a particular theoretical and operational 
stance is the label under which an analysis of culture is to be conducted. Cultures, as well as their analysis, have historically been open to a wide array of definitions and interpretations.

Perhaps the most appropriate place to begin a discussion of culture would be at the first widely recognized conscious division between that which is malleable to human endeavors and that, which is beyond the influence of human action. The Greek philosophical tradition, reflected in the Socratic Dialogues, differentiates between the physis, roughly interpreted as nature, and the nomos, or custom. (Surber, 1998)

Drawing upon this philosophical division between that which is created by man and that which is beyond his control, Malinowski (1944) arrived at a broad-ranged definition of culture as being:

The integral whole of implement and consumer's goods, of human ideas and crafts, beliefs and customs...we are confronted by a vast apparatus, partly material, partly human and partly spiritual, by which man is able to cope with the concrete, specific problems that face him.(36)

While this definition of culture is certainly broad-based and seemingly allinclusive, it addresses most appropriately the far-reaching influence of my conceptualization of the occupationally based culture of fire fighting. What I propose is that, as a matter of history, the "firefighter" has been so greatly influenced by the norms and expectations of his occupation that it has become his central identity, and therefore, his primary source of understanding the social world.

In her text Natural Symbols (1973), Mary Douglas introduces the concepts of Group and Grid as a means of understanding social influence. In Douglas' analysis, Group refers to the amount of cohesion that an individual has within a particular social 
unit. (Thompson, Ellis \& Wildavsky,1990) Therefore, the stronger the degree of group, the more likely the individual actor's behavior is to be determined by group membership.

In addition to Group, Grid is used to identify the "degree to which an individual's life is circumscribed by externally imposed prescriptions." (Thompson, 1990) Therefore, if the degree of Grid is high in an individual's social atmosphere, then he or she is less likely to find freedom in their negotiations of the social landscape.

As a means of analysis, Douglas created a graph to denote a sliding scale of measurement. As the influence of either Grid or Group moves further in either direction from the zero point there is a separation between conformity and innovation. (Douglas, 1970) In a perfectly isolated system, the mutual reinforcement of both group and grid keeps the social conditions stable and limits the amount of potential change. According to Douglas' analysis, most social situations are not sufficiently well insulated to maintain the mutual reinforcement necessary for organizational stability. In a normal situation, both Grid and Group operate on a sliding scale of influence indicating social change.

However, it is my proposal that the culture of fire fighting allowed for a sufficient isolation from external influence that negated any large-scale external influence. Based upon the combined effect of a largely unisex workforce, positive reinforcement from outside groups of internal definitions (such as "hero" and "rugged male"), similarity in economic status and social class among the workforce, and a high degree of occupational autonomy, the Fire Service was historically able to maintain both high degrees of Group and Grid in a mutually reinforcing atmosphere. According to Douglas' work if a set of conditions such as those described as existing in the Fire Service is found to exist within an organization, then a set of expectations can be cast on the development of that culture. 
Strong grid and strong group will tend to a routinized piety towards authority and it symbols; beliefs in a punishing, moral universe, and a category of rejects. Any bureaucratic system, which is sufficiently secure and insulated from criticism, will tend to think the same way. This is the monastic life, the military society. (Douglas, 87)

Based upon the theoretical expectations of Douglas' work, we can anticipate the traditional, male-male oriented fire service to be characterized these cultural markers.

1) A critical separation between in and out-group members. If there is to exist a high degree of stability in both group and grid within the firefighting culture, then membership must be both clearly defined and remain relatively constant. Dramatic change in either the definition of members or workforce composition would affect the group/grid stability and be an impetus for social change.

2) A hierarchical system of in-group classification. Based upon the high degree of socially prescribed expectations of behavior and rigid social boundaries, a hierarchical system of classification within the group can be expected to exist. (Thompson, 1990) This expectation can be clearly seen in the emphasis placed upon the "degree" of membership present within the Fire Service. As I will describe in detail in the following sections, particular attention is given to the "seniority" of an individual firefighter (based upon years of experience). Rather than basing its system of stratification solely upon an organizational structure reflecting assigned titles (Firefighter, Paramedic, Driver/Operator, Lieutenant, Chief, etc.), the culture of firefighting recognizes the subtle differences in group orientation that develop with greater degrees of interaction in a tightly maintained environment. 
3) The development of group specific rituals. In her analysis of group maintenance,

Douglas (1970) notes the critical role assumed by the development and use of rituals.

If ritual is taken to be a form of restricted code, and if the condition for a restricted code to emerge is that the members of a group should know one another so well that they share a common backcloth of assumptions which never need to be made explicit, then tribes may well vary on this basis. (78)

The development of rituals in firefighting culture thus serves at least three distinct functions. 1) It strengthens the degree of cohesion among the individual members by increasing the expectation of shared views and cultural expectations. 2) It further widens the gap between those who are granted group membership and those who are defined as being outside of that group (as I will argue later, the culture of firefighting has traditionally operated on a simple binomial system of classification, you are either a rescuer or victim). 3) A ritualized system emphasizes the importance of the agents of socialization as the key source of access to shared understanding. Such a system eliminates the possibility that any individual can become a "firefighter" based solely upon individual initiative. If becoming a firefighter includes not only the acquisition of technical skills, but more importantly, access to an understanding of the shared system of codes that are the center of the culture, it then falls upon those who have already gained access to this knowledge to socialize new members. If such a system were built upon a foundation of high group and high grid, then the introduction of individuals that had previously been defined as "out-group" would threaten the stability of that culture. 4) An aversion to change. If we construct our model of a high group/grid culture upon the guidelines previously listed, we can assume that such a culture would be reluctant to admit any form of change. Whether in the composition of its population or in 
the practice of its constituents, change in any of these forms can signal a transition of culture and community.

Taken as a whole, we can construct a cultural model of the Fire Service (FS) that has been based upon the transmission of restricted code and ritualized norms by previously enculturated members. The singular gendered expectations and composition of the FS has constructed a culture that produces high group and high grid that is specific to only one group; white, working-class males. The introduction of alternative members into this environment cannot be expected to produce the same degree of group and grid in members who do not share the same "backcloth of assumptions." Therefore, it can be predicted that women, as members of a previously excluded group, when introduced into the FS, would develop an identity that is responsive to a lesser degree of both group and grid and based upon a set of values and norms that differs dramatically from those utilized by an all-male FS.

\section{Cultural Analysis}

The analysis of any culture is rife with practical and theoretical obstacles. In order to analyze a specific culture it is first necessary to gain some degree of insight into the values, norms, and definitions of that particular social organization. Each society can be said to have its own group specific interpretations of social variables. (Geertz, 1971) It is only by gaining an insight into those interpretations, that one can hope to adequately represent a specific culture in an analysis.

In an attempt to define the theoretical stance of this research, I will rely upon the approach taken by Contemporary Cultural Studies theorists. As noted by Surber (1998) in 
his work on cultural critique, the Contemporary approach takes a multifaceted strategy when undertaking the analysis of culture. Rather than focusing on a specific facet of an isolated social phenomenon, the Contemporary approach utilizes the extensive history of theoretical platforms to piece together a more comprehensive cultural landscape.

It is my belief that by taking this approach, I will be able to meet two of my objectives in undertaking this exploratory research. By maximizing the areas open for consideration in this analysis, I will able to 1) consider the impact of a "concrete cultural production and institution" (Surber, 233) upon both the group and the individuals that comprise it. 2) Draw from a variety of different disciplines by taking into consideration a) Marxist lines of analysis concerned with the influence of class and wage labor, b) psychosocial considerations dealing with the development of occupationally based identities, and c) structural considerations concerning the formation of cohesion and identity within the group. By drawing upon these various disciplines, I intend to offer a more complete analysis of the impact of structural change upon the culture of firefighting than would be possible if I were to limit the investigation to only one area of concern. Each of these theories offers another point of insight into the cultural creation that is the fire service. By bringing them together, I intend to undertake a comprehensive analysis of organizational and cultural change.

\section{Organizational Considerations}

Organizational structure in the Fire Service (FS) has taken various forms of quasimilitary models. (Farrell, 1994) This form of structure, more commonly referred to as linear organization (ICMA, 1984) is based on the downward flow of decision making and 
the upward flow of information. In the FS, the decision making process begins exclusively at the top and descends according to rank and position.

Decision making in the FS is based upon the belief that immediate action prohibits the luxury of lengthy conversation or group decision making. Orders are given without the expectation of discussion. Such systems place a heavy burden upon those in the top positions while simultaneously removing the concern of direction from those who are left tending to the more physical tasks.

The structural organization of the FS lends directly to the occupations defining characteristic; an emphasis upon the rank and seniority of the worker. Linear models of organization depend heavily upon hierarchical roles to function smoothly. (Farrell, 1994) An individual's specific abilities or areas of specialization are de-emphasized as the universality of specific roles is relied upon to minimize the need for person-specific ability. Much like the military forms of organization that the FS has been modeled after, similarities in role responsibilities are utilized to maintain commonality in function. The role boundaries in linear models are clearly defined and respected. Every position, from Chief to Firefighter is defined by clearly labeled duties and responsibilities. An individual can be easily moved throughout the system (either vertically or laterally) without the need for gross organizational modification.

Less obvious, but perhaps of more value to the organization is the function of seniority within the FS. Seniority, which can be roughly defined as the number of years one has been working within the FS, is heavily relied upon as an indicator of both experience and value within the organization. In line with the linear system's reliance 
upon role over personal competency, the FS has traditionally relied upon the seniority of an individual to transcend concerns of individual ability.

The concept of seniority has become a cornerstone of the FS. Rewards and privileges have become solely reliant upon an individual's seniority within the system. Vacation time, station assignment, daily duties, and rate of pay have become dispensed exclusively according to this single variable.

Seniority based systems lend themselves to utilization by a largely homogeneous workforce. If the evaluation of an individual's worth within a system is to be based upon strictly objective, non-performance related markers, then the majority of the workforce must be willing to accept the commonality of their position. In addition to reinforcing a propensity towards male biased homogeneity, utilization of a seniority-based system lends itself to the support of organizational stratification (Savage \& Witz, 1992) with the greatest rewards reserved for the (usually male) most "senior" firefighters. This fact is especially significant given research findings that indicate the greatest resistance to female and minority firefighters as residing in the group of firefighters with 20 or more years in the FS. (Mcqueen, 1990).

In contrast, if individual initiative or ability are to be emphasized, the distribution of rewards and privileges must be merit based. Therefore, the structural organization of the FS prohibits the large-scale assignment of worth based upon individual qualities, and the recognition of seniority necessitates the homogeneity of role tasks. A FF in such a system must be willing to accept him or herself as exactly equal to every other person occupying a similar position. 
2) Linear systems are reluctant to embrace change. Line systems of organization depend upon similarity in function in like roles. Therefore, a change in the role of any specific position has large-scale consequences for the remainder of the organization and can "eliminate the communal basis of occupational identity that is the basis for much of the social significance of occupation." (Sullivan, 1990) For example, the recognition of Fire Medic (a Firefighter holding a state Paramedic certification) creates another level of stratification within the organization. This, in turn, necessitates the creation of clearly defined obligations and responsibilities that must accompany the creation of a new position. However, the recognition of too many roles within a simplicity-oriented system prohibits the clearly defined chain of command upon which the organization is centered. (Ahrne, 1994) Therefore, linear models of organization such as the FS must limit the degree of stratification that is recognized. The creation of too many levels inhibits the ability of the organization to function smoothly and a change in any single position will affect the remaining positions within the system.

The question of change is especially relevant given the focus of this research. Specifically at issue is the degree of disparity between administrative philosophy and occupational function. Therefore, if attempts at organizational change have not been effective on the operational level, one would expect to find the greatest amount of disparity existing between more senior, "traditional" firefighters, and the less senior, more varied, recruits.

In her research conducted in the Oakland Fire Department, Carol Chetkovich (1997) identified three distinct patterns of attitudes present among various groups within the FD recruit class she studied. The attitudes that she discusses relate to the FF's 
expectations of change (as it related to traditional values/rituals) following their

employment. Chetkovich defines the attitudes as existing along a continuum ranging from traditionalist at one extreme to change oriented at the other extreme.

Among her research subjects, Chetkovich found that three specific groups with varying expectations of change could be readily identified. For the first group, which was comprised primarily of white and Hispanic males, Chetkovich found that their attitudes could be found to range from, "extreme traditionalism to moderate change-oriented, clustering at the traditionalist end.” (50)

In contrast, Asian and African-American males tended to fall between the moderate traditionalist and extreme change-oriented half of the spectrum, with the peak grouping occurring "slightly toward the change oriented end of the spectrum."

At the other end of the range from the white males sat women of all races. According to Chetkovich's findings, the high point of this group's attitudes occurred at the extreme end of the change-oriented area with the remainder of the attitudes tapering back into the traditionalist region.

Obviously, subjects such as race and gender must be approached with the understanding that there is no singular experience or set of experiences that creates male and female, white and black. Each individual brings to the workplace a unique set of experiences and attitudes that shapes his/her understanding of the social world. However, what Chetkovich's findings do seem to suggest is an overall pattern of expectations among women and racial minorities entering the FS that clash with the organizational structure of firefighting and the masculine perspective that it embraces. 
What role then, does the organizational structure play in operational function and the development of occupational identity? Giddens' Structuration Theory (1984) suggests that the institution cannot exist outside of the human agents actively involved in the reproduction of certain social expectations. To Giddens, structure refers to, " the structuring properties allowing the 'binding' of time-space in social systems, the properties which make it possible for discernibly similar social practices to exist across varying spans of time and space and which lend 'systemic' form." (17) Following Giddens' lead, it is possible to deduce that the organizational form of the FS is highly dependent upon the transference of ritual and norms within the culturally specific realm of the FS. The Fire Service, as a unique and independent institution is continuously created and re-created by the active participation of the agents within the group. By drawing upon past practices and institutional rules and resources, the structure of the FS is directly linked to specific institutional practices. (Savage \& Witz, 1992)

If analyzed under the Gender Paradigm suggested by Savage \& Witz (1992), the institutional practices suggested by Giddens are also responsible for the creation of a patriarchal organization with an absolute stratification of power and prestige drawn along gendered lines. The FS is an organization that can be tied directly to the social creation of masculinity. Therefore, the practices and normative behaviors found within the institution are prohibitive of any change that would minimize the expression of masculinity. While the FS as an organization might be unable to prevent the inclusion of women and minority members from within its ranks, the expression of culturally specific values can be inclusive of practices that prevent the full participation and acceptance of such members. 
Overshadowing all other organizational descriptions, the FS is most certainly a bureaucracy. In his essay, "Bureaucracy", Weber (1946) outlined the characteristics of a bureaucracy. Included in this characterization are many of the same organizational attributes found in the FS. Among those attributes that mark the FS as a bureaucracy are a positional hierarchy, levels of graded authority, a base of written documents, a stable of general rules that are easily learned and passed along, a degree of social esteem that accompanies promotion, regular pecuniary compensation, and a career orientation.

In her study of The Structure of Women's Nonprofit Organizations, Rebecca Bordt (1997) further builds upon Weber's bureaucratic theory while taking into consideration the gender of the organization. According to her research, bureaucracies should be expected to function optimally when utilized by groups such as large, highly stratified, government organizations. In spite of some feminist criticisms that maintain bureaucracies function best within organizations that assume a non-feminist ideology, Bordt's research concluded that organizations that defined themselves as feminist were no less likely than non-feminist organizations to assume a bureaucratic structure.

The apparent compatibility of bureaucratic organizations and feminism, however, should not overshadow the fact that Weber's theories have been criticized for assuming a purely patriarchal stance. In her analysis of his work, Roslyn Bologh (1990) commented on the masculine nature of Weber's theories, "His represents one of the most important voices of modernity on modernity. However, there is good reason to consider this voice masculine, masculinist and patriarchal." (26)

Therefore, while a bureaucratic structure may have been an "ideal type" of organization, it can be shown to be largely representative of masculine ideals. The 
masculine orientation of bureaucratic organization, coupled with the linear models of management preferred by fire agencies can therefore be assumed to be closely related to the social orientation of men and further alienating to the women working within these systems.

\section{Women Working in a Man's World}

The introduction of women into the FS has been met with the same sort of resistance that has been noted in similar blue-collar professions. Recent studies of women engaged in the commercial fishing (Fields, 1997) and manufacturing fields (Kim, 1997) have suggested that the difficulties encountered by women attempting to integrate the FS have been reproduced in other male dominated occupations. Kim's research on the women of the South Korean manufacturing market illuminated powerful differences in the level of pay, performance, and satisfaction ranking between males and females engaged in similar occupations.

Similarly, in her study of the women of the Alaskan commercial fishing industry, Leslie Fields (1997) found substantial resistance to the introduction of women as individual contractors. The difficulties that these women were faced with were directly related to their attempts to enter into a male dominated environment in roles that would have limited their involvement to more traditional "emotional labor." (Hochschild, 1983)

Research that has centered upon the economic aspects of discrimination has generally focused upon those factors that produce protective measures utilized by those already employed in the field. From a fiscal standpoint, FS positions can be quite rewarding. With a starting annual pay that ranges from $\$ 28,00$ to $\$ 46,00$ nationally 
(Chetkovich, 1998) and the number of jobs available for full-time employment limited by local budgetary considerations, competition for jobs within the FS has become fierce.

While no less motivated by economic necessity than their male counterparts, females attempting to find work within the FS have often been accused of having financial motivation, rather than occupational value, as their primary concern with securing employment. (Summers, 41) To put it more clearly, men are perceived to desire employment within the FS due to their appreciation of the "nature" of the work. In contrast, women, when attempting to enter a male-dominated work force such as the FS, have been subjected to criticisms of their motivation for joining the workforce. This differential focus, from identification with the occupation to financial concerns has placed some new recruits in an unfavorable position within the firefighting organization.

This relationship between masculinity and occupation, and more specifically masculinity and power is a central issue with this research and a central problem for the integration of the FS. In her research on the production of gender in women's hockey, Nancy Theberge (1997) found that those opportunities for women to compete in historically male-dominated fields (such as hockey and firefighting) present a "challenge to ideologies of gender and to the historical association between gender, physicality and power." (70) As such, the wholesale acceptance of women into the role of firefighter would signify the acceptance of a gender neutral standard of performance, a devaluing of gender based standards for physicality, and the relinquishment of power by male participants.

Advocates for the full integration of women into male dominated fields do not deny the differences between the physical abilities of men and women. Rather, their 
assertion is one of deliberate exclusion and a lack of preparation for female participants. Programs such as those instituted in Jacksonville, Florida (Fire Chief, 1991) and the California Department of Forestry (Clayton, 1984) have been based upon the idea that women lack only preparation, not ability. Recognizing the differences in both physical stature and performance expectations, these programs have instituted specialized training for female participants seeking employment in firefighting.

In the case of the Jacksonville academy, those women who had previously failed the state exam and were able to complete the extra training, saw a $50 \%$ increase in passing performances on the certification examination. Programs such as these focus upon the physical limitations of female candidates and seek to overcome any deficiencies through training and instruction in proper technique. However, as some advocates of female firefighters have argued, physical preparation alone cannot adequately prepare female cadets for the male dominated field that they are about to enter. (Floren, 1990) Specifically, physical training cannot overcome the social barriers that women face in the FS. With only $5 \%$ of the national pool of firefighters being women (Yoder \& Anaikudo, 1997), the sheer scarcity of other women and the predominance of $83 \%$ of the workforce that is comprised of white males, suppresses the degree of influence that women are able to exercise once they have managed to make their way into the ranks of working firefighters.

The most direct discrimination of women in the FS occurs during the interaction of male and female firefighters. Quite often, such discrimination is considered traditional "hazing" (the ritualized exploitation and discrimination of rookie firefighters) by the 
more senior firefighters. However, it is possible that in the case of women this ritualized maltreatment assumes a much different form.

Much of the current research on female firefighters focuses on the lack of female inclusion and the potential consequences of hazing practices. Publications that have focused on gender differences on the operational level (Yoder \& Anaikudo, 1996 \& 1997; Summers, 1995; Chetkovich, 1998; Farrell, 1994; and McQueen, 1990) have found several significant differences between the hazing of male and female cadets.

One of the most significant of these differences is the degree to which the hazing or differential treatment has occurred. In their study of African-American female firefighters, Yoder and Anaikudo (1996) found that the perceived significance of any differential treatment increased substantially due to repeated occurrences and the almost complete organizational distribution. Acts that, taken alone, would have seemed almost insignificant became intolerable when placed within the larger, discriminatory culture.

The consistent nature of this discrimination is then coupled with the lack of potential inclusion upon completion of the probationary period. For most rookies, the traditional hazing period ends either following the completion of their first evaluation period (traditionally 12-18 months) or following the initiation of the next rookie class. Men are not excluded from this practice. In this matter, I can easily offer an example from my own experience. For the entire length of my first year on the Fire Department every morning shift meeting would begin with the same comment, "Q: What is the only thing in this world lower than whale shit? A: A probationary firefighter."

However, as Savage and Witz (1992) indicate in their study of Gender and Bureaucracy, such treatment takes on an entirely different persona when directed at men 
rather than at women. For most men, such treatment was a rite of initiation, the endurance of which would ultimately lead to full inclusion within the group. Never once did I believe that the remarks made to me during my rookie year were meant to be an attack on either my character or my abilities. They were accepted in a spirit of camaraderie and the promise of full acceptance.

The same cannot be said for the women that must endure similar treatments. For them, there is no guarantee of terminal acceptance. Nor is there any guarantee that this treatment will end at the completion of their probationary period. The full incorporation of women is not guaranteed, regardless of the treatments they endure.

If we take the FS to be constructed along lines of masculinity, then to be fully accepted into the firefighting culture, one must be capable of assimilating to masculine ideals. Obviously, the categorization of any potential member as feminine, let alone female, seriously limits the individual's potential for full inclusion. Dependent upon gender-based categorizations as a means of member identification, the FS has left limited room for women. In the culture of firefighting, women are the victims, not the heroes. The rituals and normative behaviors endorsed and reinforced within the firefighting culture are male based and therefore, to be considered a "true" member, one must be male.

The first female firefighter was hired in 1974 by the Arlington, Virginia, F.D. (Farrell, 1994). Spurred by equal access and anti-discrimination legislation such as Title VII of the Civil Rights Act of 1964 and Executive Order 11246, modern fire departments were unable to actively prevent the entrance of women into combat firefighting. 
However, legislation alone cannot change cultural expression, and the women who were able to secure positions within the FS were left in a from of identity limbo, performing in a role that was for all practical purposes, the antithesis of femininity.

For those women, working within the FS became a delicate balancing act of vacillating between being a firefighter and being a woman. Chetkovich's (1998) study found that female firefighters operating within the heavily masculinized world of the FS must negotiate a series of impression management techniques to prevent the application of a "girl" or "feminine" label. Women must appear, if not masculine, then at least insensitive to the rituals of a traditionally male homosocial grouping.

Women working within the FS are forced to steady their own sense of femininity with cultural expectations of "toughness" and a weariness of excessive concern with appearance. Trapped in a lesbian/whore dichotomy, the negotiation of physical appearance becomes a marker of identity and status. (Dellinger \& Williams, 1997) Too much attention to physical appearance can label the female FF as being "easy" and therefore subjected to the fears of FF spouses and the substance of rumors. (McQueen, 1990) Too little attention to her physical appearance, and the female firefighter will be suspected of homosexuality or written off as "butch." Female FFs, unlike their male counterparts, cannot escape their gender and achieve subjectivity. (DeBeauvoir, 1952) Women in the FS are inherently tied to the biological position as female and their social construction as woman. They can neither escape their gender, nor can they fully assimilate into the role of FF. They must exist as an "outsider" operating within a white, male-based system. (Yoder \& Anaikudo, 1997) 
The association of occupation with gender is built upon the interaction of tradition, ritual, identity, and social expectations. People operating within an organization construct an identity based upon occupationally defined gender expectations. (Modell \& Hinshaw, 1994) This gendered identity is then reinforced by the cultural expectations, rituals, and social organization of the group.

The introduction of women into the FS has challenged the traditional occupational identity assumed by the male firefighters and created a division between male and female that cannot be crossed by simply enacting legislative change. While Affirmative Action legislation is able to open the door for women seeking employment in the fire protection field, it is incapable of closing the rift between a male dominated workforce and female participants. The assignment of women to the "outside" world, the denial of female subjectivity, the danger associated with the occupation, and the inability of women to transcend the master status of "female" all work to prevent the full inclusion of women and to maintain the existing gender based power structure. (Novack \& Novack, 1997)

The reactions of male FF's to the placement of women within their ranks have ranged from acceptance to unbridled disdain. The American firehouse has historically been a masculine domain defined by the "banishment of women and the specter of marriage." (Greenberg, 1998) Perhaps fittingly, responses to integration have been described in terms reminiscent of Kubler-Ross' (1969) stages of acceptance when confronted with a terminal illness. In an attempt to analyze the reactions of their male FFs to the integration of the FS, one Fire Chief and his aide created a scale to mark the process of acceptance of women in the FS. (Winkle \& Navarre, 1985) According to their study, FFs faced with the introduction of female members go through four identifiable 
stages: 1) Denial, 2) Anger, 3) Non-cooperation, and 4) Acceptance. It should come as little surprise that, as in Kubler-Ross' work, the victim eventually succumbs to an inevitable fate.

\section{The Social Creation of Firefighting}

The creation of a gendered identity is a social process. Males have traditionally been tied to public expressions of gender ideals, while females have been inherently tied to their biological status. Mead's classic study of Male and Female (1949) documents in depth the differential approaches taken by various cultures as men and women struggle to ascribe meaning to their biological variation.

The identities that are created are the result of patterns of primary and secondary socialization that reinforce cultural expectations and create a base of "commonsense knowledge" (Berger \&Luckmann, 1966) that becomes a cornerstone for cultural understanding.

A central issue of this research is the relationship between the creation of an occupational identity and the relationship that that identity has with socially produced gender expectations. Firefighting is more than an occupational realm that has been historically dominated by only one sex; it has itself become an embodiment and an expression of masculinity.

This relationship between occupation and gender identity raises some very specific questions. To begin with, what factors have led to the relationship between masculinity and occupation? Moreover, what makes firefighting such an optimal expression of masculine ideals? 
In his research on the social production of masculinity, Michael Kimmel (1996) constructs a clear relationship between the public realm and the social creation of masculinity. According to Kimmel's analysis of American culture, the rejection of European culture, an obsession with "rugged individualism," a clear separation between public (male) and private (female) domains, the establishment of a capitalist economy, and the male's need for constant reproduction, were all critical developments in the development of American masculinity.

Kimmel presents three clear themes that he suggests have became the centerpieces of American masculinity. Based upon the principles of "self-control, exclusion, and escape," (44) the American male has constructed a gender identity that had its infancy in the Revolutionary War and continues to this very day.

Firefighting, much like the American version of masculinity, is based upon the constant validation of gender and a clear separation between men and "others" that occurs in a public realm. As such, the creation of this gendered identity is largely dependent upon the public expression of action, the difference between what Mead (1949) termed "being" and "doing."

Action based and gender-specific, the FS adopts an overtly masculine attitude towards all tasks. The persona of the American firefighter is most accurately described by the nine characteristics of Keen's (1991) Warrior Psyche.

1) A dramatic, heroic stance. The American firefighter must be able to overcome overwhelming odds with confidence and bravery. Much is made about the dangers that come with the job. Firefighters are America's heroes and they take pride in that title. 
2) Willpower, decision and action. Firefighting, like masculinity, is action based. It is built upon the principles of moral righteousness and certainty of action. Firefighters see honor in their occupation and pride in their reputation as heroes able to overcome tremendous odds.

3) A sense of adventure, excitement, and heightened awareness that comes from living in the presence of death. A central theme in firefighting culture is the importance of group cohesion and the reliance upon other firefighters that develops in high-risk occupations. (Cargill, 1996; Chetkovich, 1998) This cohesion is seen as a necessary ingredient of group performance in situations that have the potential for great personal sacrifice. Studies conducted by the United States Military on the role of cohesion in group performance concluded that high levels of group cohesion are "essential for organizational effectiveness" (5) and a singularly important factor in determining combat success. (Johns, 1984)

This same study identified the importance of group cohesion in high-risk activities as a solidifying agent, bringing the group together and sustaining "their will and commitment to each other, their unit, and their mission." (ix) This moral commitment to the group was then found to result in a dramatic increase in the degree of internalization of values, norms, and sensitivity to the social sanctions of other group members. This form of organization cohesion, termed an Institutional Model, is typified by high levels of moral commitment, identification with the group, and association to the norms and values of the organization. In contrast, the Occupational Model that is commonly associated with increased bureaucratization and scientific management places and emphasis upon 
increased careerism and managerial behaviors, a shift that was identified in Johns' (1984) research as being directly tied to a decrease in the intensity of group cohesion.

The firefighting community, much like the military organizations upon which it was modeled, is highly dependent upon high levels of group cohesion to function smoothly. Commonly referred to as a sense of "family", this cohesion has been identified as a critical factor influencing both occupational performance and job satisfaction among both male and female firefighters. (Farreil, 1996)

4) The identification of action with force. This is clearly reflected in the firefighter's action-based philosophy. Consider the statement made by one firefighter being interviewed for a book on the profession, "Everyone wants to be the guy on the nozzle [lead position in a fire attack]. There is nothing else like it. You are the guy with the weapon in his hand. You're the guy who is going to put this thing out. Yeah, you want the nozzle. That's the place to be." (Delsohn, 112)

5) A paranoid worldview. This is most closely reflected in the negative reaction to legislative intervention in workforce composition. In this scenario, the homosocial environment of the FS is the "commonsense" arrangement that is based upon natural ability now threatened by outside intervention. Persons entering the FS that do not fit the typical firefighter idealizations are suspect of having less noble motivations for desiring entrance and of manipulating the system to gain employment.

6) Black-and-white thinking. As has been previously discussed, para-military organizations such as the FS place an emphasis upon following the "chain-of-command" and group participation. In the culture of firefighting, you are either right or wrong. There are few shades of gray. Those who adhere to the norms of the group and adopt the central 
identity are given a great deal of leeway, while those individuals that maintain a more individualistic stance are separated from group and targeted for punitive action. (Cargill, 1996)

7) The repression of fear, compassion, and guilt. The use of humor to deal with emotionally difficult situations, reinforce group hierarchies and norms, and solidify group boundaries has been well documented. (Cargill, 1996; Walker, 1998) In an occupation that exposes its workers to a great deal of tragedy, humor is utilized as a replacement for the more "feminine" compassionate or empathetic approaches.

I was able to observe this interaction quite clearly when I witnessed a series of interactions between a veteran firefighter and a rookie E.M.T. that had just returned from a difficult call.

The crew had been called to the home of a woman who had suffered a miscarriage. When they arrived, the patient was seated in a chair and appeared to be quite calm. After some discussion, she told the crew that she had earlier experienced a miscarriage and required assistance to the hospital. After some conversation between the Paramedic and the patient, the patient stood to walk to the stretcher. It was at this time that she revealed the fetus that was still attached to her by an umbilical cord that dangled slightly between her legs as she walked.

After returning to the station, the rookie crewmember began asking a series of questions about the patient and her condition. He was obviously troubled by what he had just witnessed and had turned to the more senior Paramedic for an explanation. After allowing the rookie to ask a series of medically related questions, the senior Paramedic on the crew interrupted the new member and suggested that his concern was misguided. 
"After all", he said, "it could work in her favor. She could use the fetus in her act as a tittie-dancer." He then jumped up on a table and began dancing with a mock fetus (a remote control dangling from a piece of tape) hanging between his legs.

Through this interaction, a variety of group values and boundaries were both transferred and reinforced. The message in this humor is that the biological or psychological concerns of the female patient were secondary to her position as a sex object. The boundary between male rescuer and female victim was firmly reinforced as compassion was placed in a secondary role to humor and group interaction.

8) Obsession with rank and hierarchy. The organizational structure and the function of a seniority based system serves to distribute the rewards disproportionately to those in the upper classifications while simultaneously reinforcing the power and normative structure.

A strong organizational hierarchy rewards male characteristics (such as confrontation and a desire for dominance) pushing males into the best positions. Research on gendered organizations suggests that this trend remains true regardless of the relative proportion of men working in the field. (Williams, 1995)

9) The degrading of the feminine. The degrading of feminine qualities and attributes serves several functions in a masculine culture. In accordance with the separation of public and private realms, the masculinization of traditional tasks permits the completion of necessary duties without comprising definitions of acceptable behaviors. Dishwashing, laundry, the cleaning of floors and other household duties can be performed in a masculinized manner that permits their inclusion in a gender specific environment without necessitating a change in member identification. 
A negative connection with femininity can also be found in male dominated groupings in the form of homophobic behaviors. Jokes, suggestions, and accusations of homosexuality are all utilized by the group as a threat of a possible rescinding of masculine status, rather than a realistic concern about an individual's sexual orientation.

As Lehne (1997) suggests in his research on the function of homophobia, "Since any male could potentially (latently) be a homosexual, and since there are certain social sanctions that can be directed against homosexuals, the fear of being labeled a homosexual can be used to ensure that males maintain appropriate male behavior...homophobia is a threat used by societies and individuals to enforce social conformity, and maintain social control." (245) Therefore, the use of homophobia is not as much an attack on a person's suspected sexuality, as it is a threat to remove masculine accreditation.

The American version of masculinity that is continuously reproduced and exclusive to the public realm produces an optimal working environment for the FS. So closely related are American masculine values and the occupational identity of the FS that an individual working as a firefighter can benefit from a sori of de facto masculinity where membership alone serves as a flag of machismo. 


\section{DEPARTMENT PROFILES}

Three separate South Florida fire departments were utilized during the commission of this research. All three departments employ full-time (professional) firefighters, Emergency Medical Technicians, and Paramedics. In addition to providing emergency medical and fire combating services, all three departments maintain Hazardous Materials teams (for chemical and specialized operations), public information departments, and fire prevention services (such as code development and fire inspections). Two of the departments are county administrated, providing services for smaller towns without the resources or desire to maintain their own fire departments and unincorporated rural areas, and the remaining department is overseen by city administrators, with primary attention given solely to the members of their community. In order to assure the arionymity of the research participants and the confidentiality of delicate information, the names of the participating agencies have been changed.

The largest of the three departments will be referred to as Long Trail Fire Rescue. According to current information, they currently empioy over 1,634 firefighters and support staff. Long Trail serves a diverse racial and cultural population spread over 1,924 square miles (including unincorporated areas and 25 municipalities) and consisting of more than 1.9 million people.

Following the lead of the Chief Officer, Long Trail Fire Rescue has begun a series of hiring practices designed to improve the gender, racial and ethnic diversity within the department. They claim to be aggressively working towards a workforce that reflects the 
gender and ethnic composition of the community they serve. However, despite this move towards a reflective workforce, inquiries into the actual composition of the workforce were unanswered. Therefore, I am left with no actual measure of the success of this change in hiring practices.

The other county agency utilized for this study is Unified Fire Rescue. Like Long Trail, Unified F.R. serves a large geographical area consisting of over 550 square miles (including 13 municipalities) and a varied population of over 560,000 people. They currently employ over 900 Firefighters and Paramedics.

Unified does not currently alter their hiring practices to benefit any single group. Their workforce is drawn from a pool of qualified applicants who are run through a series of standardized physical and written tests, and oral interviews. Each applicant is assigned a numerical score based upon his or her performance in each of these categories. Positions within the fire department are then distributed to those individuals with the highest scores. Based upon current numbers supplied by the fire department, Unified's current workforce is comprised of $93 \%$ male and $7 \%$ female firefighters.

The last of the fire departments is the only city run agency in the study. Big Town Fire Rescue is a municipal department consisting of approximately 137 firefighters and support personnel. They serve a population of more than 53,000 persons covering 15 square miles.

Of the three departments utilized in this study, Big Town is the most reliant upon individual interviews and qualifications when hiring. Discussions with their Assistant Chief revealed a department philosophy that embraces progressive thinking and the ability to assimilate to foreign environments. They are the only department in this study 
currently employing psychological evaluations in the hiring process. Current estimates concerning the sexual and racial composition of the Big Town F.D. show female firefighters as comprising $10 \%$ of the currently employed workforce and minorities (not including women) occupying another $20 \%$ of F.D. positions.

\section{RESEARCH METHODOLOGY}

Taken together, the three South Florida area fire departments utilized in this research provided a sample population of 2,671 firefighters and support personnel. For the purposes of this research the terms firefighters and support personnel will refer exclusively to any individual currently employed as a full-time Firefighter, Paramedic, Emergency Medical Technician (E.M.T.), Driver Engineer, or administrative staff. Additionally, due to the current requirements of all three departments for all newly hired firefighters to maintain at least an E.M.T. certification, the terms Firefighter and Emergency Medical Technician are understood to be synonymous.

From this pool of possible research subjects, 27 volunteers were interviewed in a semi-structured format that was chosen based upon the need for the freedom to allow individual volunteers to expound on their own personal histories and experiences. This format has the additional advantage of allowing the researcher to pursue areas of interest that might arise during the interview process (Babbie, 1995)

While the limited size of the research sample inhibits the ability of the research to reach firm and valid conclusions, problems associated with access to research subjects and information (See Appendix 3) and the strength of the participant observation should 
help to compensate for the weaknesses associated with a small sample size. Additionally, while conscious of the research implications predicated by the use of a non-probability, purposive sample such as the one employed in this study, the use of more reliable probability sampling methods was negated by the large study population and the inaccessibility of much of the research pool. However, the utilization of a nonprobability, purposive sample should not invalidate the significance of the conclusions that are based upon this study. The strength of this research lies in my capacity as a participant observer and the identification of cultural markers that were differentiated in this role.

Volunteers for the research interviews were acquired through one of two different methods. In the case of the Long Trail Fire Department, the department administration was unwilling to allow unsupervised access to their firefighters. Therefore, subjects were acquired by the department through responses to a department-authored announcement (a copy was not provided). In this case, the names of volunteers were collected by a fire department official and meeting times and locations were scheduled by the department in advance. This method of solicitation produced nine volunteers. From these nine volunteers, seven were interviewed and the remaining two did not arrive for their appointments.

Both of the remaining two fire departments (Big Town and Unified) were willing to grant full access to their crews and stations. Unlike the Long Trail Fire Department, which would not allow for contact with on duty personnel, both Big Town and Unified were agreeable to the solicitation of subjects on duty and in-person. The remaining 
twenty volunteers were acquired as the result of either direct solicitation or through referral from previous volunteers.

The interview process was conducted over a period of three months beginning on August 16, 1998 and ending on November 1, 1998. Firefighters were interviewed at a variety of locations including fire stations, department headquarters, and private homes.

Of those who volunteered for the interviews, thirteen were female and fourteen were male. Of the thirteen females, there were 3 Firefighter/E.M.T.'s, 6 Paramedics, 1 Special Assistant, 1 Lieutenant, 1 Diver/Engineer, and 1 Chief. The experience of the female volunteers ranged from $1-18$ years with a mean of 8.53 years. The age of the subjects ranged from 28-39 years with a mean of 33.25 years. Of the thirteen females, 6 had been introduced to the fire service (as a career) by either close friends or family members, and 7 had come to the service through personal investigation. Twelve of the female volunteers were White and one was African-American.

The statistics for the male volunteers did not differ significantly from the females. Of the fourteen male volunteers, 4 were Firefighter/E.M.T.'s, 5 were Paramedics, 3 were Chiefs, and 2 were Lieutenants. The experience of the male volunteers ranged from 1-28 years with a mean of 13.0 years. The age of the subjects ranged from $28-44$ years with a mean of 36.27 years (with two not responding). Of the male volunteers, 5 had been introduced to the fire service career by either friends or family members and 7 had come to the service through their own investigation (with two not responding to this question). Eleven of the male volunteers were white, and three were African-American. A complete list of research volunteers appears in Appendix 1, along with the basic demographics mentioned above. 
Each interview was conducted utilizing an interview guide. (See Appendix 2 for sample) In addition to the basic demographics mentioned earlier each subject was asked to relay information that included their motivations for coming to the fire service, their understanding of the nature of "firework" prior to and following employment, their experiences as a firefighter, their opinion of the relationship between gender and ability, their satisfaction with the job and the importance of "family" as defined by the group. While not singularly concerned with gender, the interview process utilized gender as springboard for the presentation of other relevant issues.

The analysis of a culture or community necessitates a deep understanding of the values, rituals and procedures of the group. Such an understanding, even if full access to the total sample population had been granted, would probably not have been possible if this research were reliant solely upon the experiences of the volunteer interviews. It is in this area of the research that I feel my experience as a participant-observer has been of greatest benefit. As a eleven year veteran of emergency medicine (three years as an Emergency Medical Technician and eight additional years as a Paramedic) and an eight year veteran of the Fire Service, I have been well assimilated into the culture of firefighting. My experiences and interactions as a member of this unique community have provided me with unusual access to the processes and interactions upon which the culture of firefighting is both constructed and maintained. It is through this role, as a participant-observer, that I have been able to gain the majority of my understanding of the fire service as both a community and a culture. While remaining cautious to remain as objective in my analysis as possible, I am optimistic that my long history of experience 
with this group will provide the deep understanding of the structural and cultural processes that is needed for such an analysis.

\section{RESEARCH FINDINGS}

\section{Division among Women}

The interviews with female firefighters reveal several experiential patterns. Based upon the work histories of the interviewees, it is possible to construct several patterns of organizational distinctions.

The first, and perhaps most relevant pattern to develop was the division between older, more senior firefighters, and those who were more recently hired. I was not prepared for the existence of an in-group division based upon seniority. It seemed far more likely that any rift between coworkers would have appeared between the discriminatory male workers and the less organizationally powerful female firefighters. While this is not meant to suggest that discrimination did not take place along the expected male/female gender lines, the existence of this in-group division remained prevalent throughout the interviews.

The main point of contention between the experienced female firefighters and their more recently hired cohorts appears to be the perception that the newly hired firefighters are motivated more by financial concerns than love for the job, and a sort of "softness" where newly hired women are perceived as utilizing gender as a tool to prevent the assignment of particularly difficult duties. 
The attitude among the more senior female firefighters that I interviewed was more one of acceptance than an expectation of change. They took pride in their ability to complete any task that was assigned to them and to assimilate to the male environment. Consider the opinion of one female firefighter when questioned about being the only woman in an all-male environment.

\footnotetext{
I was willing to adapt...I mean I'm not going to come into a service where I am the only woman and expect everyone to change...I don't mind using the bathroom with twenty men as long as they're not in there watching me take a shower...Y You should expect coming in, the way it was...It was that way before you came...There are not a lot of women that I enjoy working with...I feel that they just want to get here at 7:00 a.m. and leave the next day. (FFF6)
}

\section{Working Among Men}

It is possible that this division is based more upon the experiences of the senior female firefighters than the actions of their less experienced cohorts. As was expected, those female firefighters that paved the way for today's recruits were met with a high degree of animosity once they joined the working crews. The initial reaction of the male firefighters to women in the stations was at once angry and exclusionary. Those early women firefighters were forced to contend with a workforce that was reluctant to change and expressive of their displeasure.

I remember, the very first week or two, you know, you do the morning chores or whatever....and one of the firefighters comes out of the shower naked, and I'm doing the 
floor...Yeah, he knew I was there...He was one of the one's I knew for a fact was not pleased with me being there...He was one of those people who was trying to hit your buttons, to see how far he could go... This thing of coming out of the shower naked, and I was sweeping the floor...I did nothing about it...It turned out to be kind of nothing, because I didn't do anything... But I didn't feel like I could do anything. I was told by people outside of the department that I was being hired and their intention was for me to never pass probation...So I wasn't going to do anything. (FFF1)

This feeling of powerlessness in the system allowed for the exclusion and active discrimination of women by their male coworkers, without a structure that was receptive to their complaints.

\begin{abstract}
When we were hired fifteen years ago...it was more of a "just do your job" atmosphere..."Don't make waves"... If you wanted to keep your job you had to do better than the guys just to be perceived as equal...But now the women would make a complaint...there is more of a system in place... They wouldn't put up with it...I hear about some of the things that they [new hires] complain about now and I think, man that's nothing... You should have seen what we had to put up with. (FFF1)
\end{abstract}

As an odd side note to the establishment of a non-discriminatory workplace, the policies and procedures implemented by the FS administrators to prevent gender based harassment, have been perceived by some female firefighters as a misused tool to change the culture of firefighting.

This is a man's job...that is $100 \%$ true... if you are a woman, you are coming into a man's job here... That's one thing I hate is when a woman comes in now and they try to change it...I mean it's been a man's job for how many hundreds of years now? And they try to change it. (FF6) 
While sometimes appreciative of the presence of a masculinized workplace, the female firefighters in this study were not free from the discrimination and role separation that comes from being an outsider within a homogeneous workforce. They repeatedly relayed tales of having to "prove" themselves both physically (by performing some difficult task) and mentally (by maneuvering through difficult situations).

Often the messages that they were entering a hostile environment began in the training academies.

I don't think it was necessarily just to exclude, which was a big part of it. But I think it was more intimidation, because they were just, you know, intimidation by the guys teaching the class that didn't want the females there. They [the instructors] were there to show you that you can't do this. (FFF2)

When questioned about their motivations for pursuing a job in the FS, the responses from the women firefighters mimic those that have been reported by studies involving male firefighters. (Chetkovich, 1998; Farrell, 1994; \& Cargill, 1996) These values include the exciting nature of the work, the variable work conditions, the structured working environment, and most importantly, the feeling of a "family" environment. This emphasis upon family was reported by all of the female firefighters interviewed as being a motivational factor in their desire to secure a job in the FS. Unfortunately, once on the job, the highly masculine styles of interaction often left the female firefighters feeling excluded. Such masculinized patterns of interaction, which include banter, joking, teasing, playful put-downs and an avoidance of one-down 
positions (Tannen, 1984), as well as the masculinized subject matter that dominated the interactions of firefighters, often excluded the participation of women.

I think that part of it is...I learned about football...This was like a guy thing...I really didn't take it as being purposeful or maicious, It's just like, after a while, if I would have been included, I would have been shocked. (FFF1)

The frustration with male patterns of interaction extends to attempts by the women (sometimes with the full support of their male coworkers) to affect positive changes in the department. Consider the efforts of one firefighter in trying to have a separate bathroom placed in the station. After spending a considerable amount of time and energy in bringing attention to the need for separate facilities at a station with 5-6 men and only one woman, she finally was granted a meeting with one of the chiefs to discuss the issue.

The Deputy Chief finally called and I finally realized it was hopeless when he said, "He had studied the question", he goes, "Would you like to be stationed somewhere else?" I said, "No, I'm, certified to be at this station, this is where I want to be." He just said, "Well, why do you have to go to the bathroom in the middle of the night anyway?" Here is the Deputy Chief of the Fire Department and he wants to know why I would have to use the bathroom in the middle of the night. That's when I knew I had no hope...I guess now I'm just at the point where I don't care...I've just felt this frustration...It's very male dominated, there will never be an even playing field. Who am I trying to kid? I came into the fire service with a lot of enthusiasm. Now it's pretty much dead. (FFF3)

It is important to note that the majority of the women interviewed did not feel that they had been maliciously discriminated against throughout their careers. Even though they were able to relate experiences of "testing" by their male coworkers in physical situations, most of the female firefighters felt that this testing would be expected of any 
rookie and were themselves concerned with the physical abilities of their coworkers. However, perhaps unlike their male cohorts, the female firefighters felt that physical ability was more tied to training and technique, than to gender or size.

Although the majority of those interviewed indicated that they had suffered no direct discrimination, in at least one instance there was a very dramatic example. After successfully completing her training period, this female firefighter was on duty when her crew was dispatched to a large, working fire.

We got to a fully involved wood frame house...First in, but we're on Rescue...So, he [the officer in command of the scene] is doing the scene size up and he comes back and says to my partner, "Give me the K-12" [a large circular saw used to gain entry]...."FFF4, you stay here. Sit by the truck"...I had to just sit by the truck...I never asked him why...I just let it brew. (FFF4)

When questioned about the role of sex in the FS, the most common response was that it is simply not an issue. As one of the firefighters stated:

After a while, it is almost like they become your brothers. I sometimes will have friends come by the station and they will be like, "How do you work around all of these good looking guys all the time?" and I'm just thinking, who is she talking about? (FFF1)

It is interesting to note, however, that of the two female firefighters with husbands in the FS, both commented about their inability to trust the working conditions when there were women in the station. 


\section{The Sexual Division of Labor}

The most crucial pattern to develop during these interviews was the relationship that appeared between women and the medical aspect of the FS. First introduced to the FS in the early 1970s, emergency medicine (represented by Paramedics and Emergency Medical Technicians) has become a centerpiece of the modern fire department. All three of the departments utilized in this study employ Paramedics. As is usual in most departments, the Paramedics are not assigned to work on the fire engines. They spend the majority of their duty day engaged in medical endeavors, working from a specialized rescue truck. Much like a mobile emergency room, the rescue truck comes complete with a variety of medications, first aid devices, and transport capabilities. During the interview process I began to question whether the introduction of emergency medicine into the FS has allowed for the indoctrination of more "feminine" qualities (such as empathy and compassion) and created a niche that would allow for a sort of escapism for women working within the FS. Such a division, if found to exist, would allow for the separation of both women from the "traditional" FS and of femininity from "fire work." Of the eight women questioned about the division of fire and rescue work, seven felt that the introduction of emergency medicine into the FS at least "lessened" the impact of the introduction of women and all agreed that women were judged less harshly when 
performing in that capacity. Additionally, three of the women expressed a strong preference for the medical side and two of those three could not see changing their assignment for the remainder of their FS careers.

\section{Gender and the Construction of Occupational Identity}

The value of firefighting, as an identity, also appears to differ along gender lines. To the women interviewees, being a firefighter is simply another in a long line of roles that they play in their lives. Rather than becoming the all-encompassing identity that has been suggested for male firefighters, the women in this study tend to view their place in the FS as a professional function.

I don't think I have ever seen a woman "become" a firefighter. I think women tend to approach this like they would any other role that they have. Whether it is mother, wife, or firefighter, it all depends on the situation. It is the men who connect with the identity. I've seen scrawny little nineteen year old boys come into the training academy and as soon as they get that badge on their chest their like, "I'm a firefighter" [puffing out her chest]. Women just aren't like that. (FFF9)

I see more men that completely identify with the job...They eat, sleep, and breath it...If you look around you don't see as many women that just eat, sleep and breath the job...They just do it. (FFF7)

Despite the problems that females have had while trying to make progress in the FS, those women who volunteered for the interviews were positive in their analysis of the impact of women in the FS. While the qualities attributed to the introduction of women 
ranged from the aesthetic to the intellectual, most centered upon the FS' need for more traditionally feminine qualities.

Our job is public relations. You can't be a spit chewing, fart blowing guy all the time...It's good because women soften up these guys. (FFF2)

I think that men in the FS think more highly of women in general...because of what they see we are capable of doing... They see we're not the little weaklings they think we are and we don't need to be taken care of. (FFF3)

I think it's probably just, I don't know. I don't think we're any better because we have women...but I don't think that we are any worse either. (FFF8)

I love to help people. That's what I identify with, the people part of it... Being able to help the community and help people that may need bandaging, they may need the emotional support... I think women are better at it. I don't know if it is a mothering thing...I think the women tend to be more empathetic. (FFF11)

\section{Gender and Group Cohesion}

Perhaps of greatest significance is the consistent disappointment that the interviewees expressed when questioned about the feeling of "family" within the FS. While all of the women interviewed offered the "family" atmosphere as a motivation for coming to the FS, all expressed some degree of concern with the way that that expectation has been met. Comments such as, "It's not how I thought it would be... I thought it would be more like a family" (FFF6), typify the experiences of the female fire fighters. While this is not meant to suggest that women in the FS are incapable of 
achieving the sort of strong group cohesion that would enable a "family" atmosphere, it does suggest that the difficulties faced by women in the FS have created a negative impact upon the development of such cohesion. It should be noted, however, that the degree of satisfaction with the "feeling of inclusion" increased dramatically during interviews with the female firefighters from the one, smaller, municipal department. While representing only three of the interviewees from their agency, all three of the female firefighters claimed to be well accepted in the "family" of firefighters.

\section{Structural Change, Cultural Transformation, and Group Cohesion}

As a contrast to the experiences of the female firefighters, several male firefighters of various seniority and rank (including one key informant) were asked about their experiences in the FS.

Similar to the opinions of the female firefighters interviewed, most of the males expressed a belief in similar values and motivations for working within the FS. Among the most commonly expressed values that were associated with working at the fire department were, honesty, loyalty, a commitment to community, selfiessness, and teamwork.

The male firefighters also expressed a deep concern for the loss of cohesion among individual members that has taken place among the modern FS.

The one thing that has changed over the years...the close knit family type group we use to have five years ago is not there anymore...It use to be when you had a station company of 4-5 people you really knew a lot about everybody...The social interaction 
has changed dramatically... a lot of it has to do with the size of the department...It's changing, you can see it change. At first, it was a brotherhood, the early fire service. It was like a club. Then it was like a really close family. And now, I almost get the perception, it's a close knit group, but it's not the same family atmosphere that I came on the department with...Is it better? I don't think so. I liked it that way. That's the way I grew up. Can we make it better? I think we can soften the blow a lot. (MFF7)

Similar to the example above, a stratification of beliefs could be seen in the expressed feelings of those who were interviewed. Drawn along lines of seniority and work experience, those with the greatest number of years on the job expressed a belief in the existence of a "family" atmosphere, with a dramatic drop in the level of cohesion that is present. Consider the following examples. The first two are from male firefighters with $28 \& 20$ years of firefighting experience and the other 2 from males with less than three years experience.

I think a lot of the changes I've seen, sadly to say, I think the camaraderie is gone...It was considered your second home... This job now, it has become your second job...I is looked upon as, 'This will be for my benefits. I've got to work at the fire department.' People are working harder... and honestly, a lot of guys resent coming to work with the women. You know you're out doing your hose testing...And you know, your thinking, "Are these women going to carry their load?"...then they get a rescue call and they leave and people resent it... Back in the old days you use to look forward to coming to work. (MFF1)

I think of it as my extended family...I think it's changed some... I get a little frustrated sometimes with some of the people we do hire now. But you know, we do have a lot of people who do some good things too. But then you have the ones that are here just looking for a paycheck. (MFF3) 
Unlike other jobs where you just come home at night and leave that other world at home, you're here for twenty-four hours at a time. You live with these people, you eat three meals a day with them, you sleep with them, you respond to stressful calls with them. I probably spend more time with my fire department colleagues than I do with my wife. This really becomes a second family, a first family almost. (MFF4)

It's a great feeling, you really feel lucky. You feel special...Everyday I think of how lucky I am to be in this profession and to be inducted into this family...I get so much gratification out of that...you know, for me, that's what makes me happy every day.... is to think that, "Wow, I have such a great job!" This is such a big family and things are so good here that I kind of, um, thank my lucky stars every day. (MFF6)

What quickly becomes evident during the discussions with the male firefighters is the difference in their belief that the family atmosphere still exists. Even when the differences between the more and less senior members are accounted for, the male firefighters regularly expressed a greater recognition of both the importance and presence of "family" when compared to their female counterparts.

For the more senior male firefighters, the greatest contributing factor in the change in family orientation has been the introduction of new members (necessitated by growth and equal access) and the growing emergence of emergency medical services.

This, however, should not negate the fact that the feeling of belonging to a firefighting "family" remained significantiy more pronounced among all members interviewed. Unlike their female counterparts, the male firefighters in this study continued to identify with the fire service and to adopt a more "privileged" connection in their association with firefighting.

It kind of compares to a fraternity...that sort of thing. (MFF8) 
I like the camaraderie. I like the family. I like the work. It's all about being there when people need you (MFF9).

It means prestige. Because, since I have been working in the Fire Service, I've been very beneficial to my community. (MFF10)

It's a brotherhood...It's a family...It's a privilege. First and foremost you're a firefighter...I'm always a firefighter, 24 hours a day, every day. That is very important to me. (MFF5)

\section{Men and Physicality}

As might be expected from the masculine nature of the FS, the attitudes of the males, either directly or indirectly, reflect a belief in the inferiority of the female firefighter's ability to perform the more physical "traditional" firefighting tasks.

When it was strictly a fire department, I think it was certainly an all male entity. But now with EMS, women are certainly capable of performing in that role equally as well as they are in a fire. They are able to respond more on a par with men in that way, on the rescue side. (MFF4)

I don't think that they will ever be completely accepted because, without sounding like a chauvinist...I don't think that the overwhelming majority of them could put up with the day to day rigors of doing the it. You can train anybody to do anything...but the majority of them just can't...I don't think that the guys accept them and I don't think that they accept a lot of the guys. They think that they're a lot of macho freaks and the guys go around and think, "Well you can't handle the job anyway because you're a female". Most of them are not that good at firefighting. I think that they're here number one to prove a point. (MFF1) 
Complicating matters further is the change in the physical standards used for testing recruits that have changed in recent years. Traditionally, rigorous physical standards were used as a tool of elimination, to "weed out" the less physically capable candidates in favor of those with more brute strength. However, as the FS was faced with the dilemma of integration, the relevance of those standards was called into question.

The first recruit class of primarily women had a failure rate of $98 \%$. When we realized that the females were failing out because of physical standards, we had to go back and review out testing procedures. What we found out was that they were unable to perform as well as the men on tasks that required a great deal of upper body strength... We looked at the tests and we were able to identify one requirement in particular that eliminated a lot of the women...After looking around our cities, we could see that this requirement was just not necessary. So we eliminated that portion of the test. (MFF12)

The lessening of standards, whether practical or not, has had a negative affect on the firefighters as a group. An increase in heterogeneity has also meant a decrease in the level of cohesion among coworkers.

You're working now with people that you might not have chosen to work with...Are we as tight? No. is that necessarily bad? No. Because we're not tight for all of the right reasons. We're not as tight because we're bringing in diversity. If that means the family's a little less close knit then so be it. Legally you can no longer utilize the old parameters that kept it close knit. (MFF2) 


\section{SUMMARY}

The fire service was built upon norms and methods of social construction that closely paralleled American values of individuality and white, working-class masculinity. Its long isolation from technology and change, and a pattern of strong public support allowed the FS to maintain a consistent pattern of social and cultural reproduction. The homogeneous nature of the workforce and the strong sense of identity present among those engaged in the occupation allowed for the development of a firefighting population that, until recently, has been free from the abundance of external influence that can signal the death of a community. (Adams, 1980) This external influence, in the form of legislative change and the introduction of previously excluded members, has impacted the group by decreasing the level of personal identification that is present within some members and by decreasing the emphasis upon family among others.

The frustration expressed by the female interviewees results both from the transformation of the community and from the individual worker's inability to escape the gendered expectations and sex stereotyping that has followed women into the fire service. The negative associations often made with the motivations of female firefighters closely parallel the gendered responses that met women attempting to integrate the world of business executives. (Harlan \& Weiss, 1982) Rather than be accepted for their dedication to the job, female firefighters must battle the perceptions that they are motivated by other, less noble concerns.

The use of female firefighters in this study is not meant to suggest that the introduction of women into the firefighting workforce is the main impetus of change. 
They have been utilized because of the stark contrast between the masculine foundations of the FS and the socially defined attributes of women.

The FS has entered a period of change that has been driven by a variety of factors. The increased utilization of technology, the growing numbers of personnel required to maintain adequate staffing levels, the introduction of EMS into the Fire Service, and the elimination of barriers preventing women and minorities from joining the workforce have all contributed to a change in the traditional firefighting culture.

Female firefighters and others entering the modern fire service are no longer bound by the same intense levels of group and grid that once typified the firefighting cuiture. Lacking a similarity of experience, and excluded from full participation on the basis of gender, the female firefighters in this study expressed a lesser degree of cohesion (group) and reverence for group norms (grid) than the male firefighters.

The introduction of EMS has provided an alternative to the traditional FS that is more accepting of women and femininity. Unable to escape the label of their gender, the female firefighter has found herself connected to the medical side of the FS where the more traditionally feminine qualities of empathy and emotional expression are condoned.

There has been a division of the fire service that exists on a very basic level. The primary division that has occurred has been between the traditional male firefighter and the women that join the FS. Regardless of their abilities, the women entering into this field must battle the perception that they are physically unable to perform the task, socially unprepared for life as defined by men, and driven by financial concerns. Any possibility of equality for male and female firefighters has been hampered by the masculine nature of the job. Regardless of individual ability, women can never be men. 
Firefighting is based upon group-specific ideals of masculinity and the profession's close association with these values. Women entering the FS must be prepared not only to prove their ability to do the job, but also their ability to assimilate to a masculine occupational identity.

The division of labor in the FS has occurred along gendered lines. Women, and to a lesser extent, minority males, have been forced to survive outside of the realm of full inclusion either in alternative roles or with limited membership. The Barnard-Simon Theory of Organizational Equilibrium (1961) suggests that members of an organization will continue to participate as long as the inducements they receive are sufficient to counter the contributions that are made by the individual member. If the inducements offered are no longer sufficient to induce adequate contributions, the organization will cease to exist. For firefighters, the inducements that have traditionally been valued have been largely psychosocial in nature. The organizational changes that have taken place in the FS have inhibited to ability of the organization to induce the individual members utilizing traditional means. The resulting division in the workforce has been the result of a multitude of social variables, resulting in differing levels of acceptance and identification. 


\section{CONCLUSIONS}

The limited sample utilized in this research and the specificity of regional experience limits this research to an exploratory study. However, the length and intensity of the participant observation, coupled with the experiences of the volunteers produces several distinct themes that should be considered.

1) The Fire Service has entered a period of cultural change. Driven by the structural, social, technological, and political changes of the last three decades, the Fire Service has seen an integration of its workforce. The resulting conflict between the traditional firefighting culture and the new members has initiated a period of cultural change. 2) The group specific patterns, values, ritualized interactions, and norms of the dominant group have inhibited the ability of outside members to assimilate to traditional firefighting culture. The traditional firefighting culture was based upon a backcloth of "commonsense" knowledge that was specific to a limited group of individuals. Once the Fire Service was opened to all members of society, the patterns of interaction that had previously dominated the culture of firefighting no longer facilitated the interaction of a heterogeneous workforce.

3) There exists a cultural division among firefighters. Based upon the limited utilization of traditional patterns of interaction and identification, the Fire Service has been divided along social lines. The white male remains the dominant group engaged in the occupation of firefighting. As such, there remain many opportunities for this group to identify with the traditional firefighting culture. However, the specificity of socialized patterns of interaction within this group limits the ability of new members to assimilate to these 
norms. Even when the majority group is accepting of the new members, the ritualized interactions of the group could be foreign enough to effectively deter outgroup

participation. The experiences of the female interviewees as they attempted to adapt to a world of "football and hunting" suggest a limited range of identification with such group specific organizations.

4) There exists a degree of difference in the level of adherence to traditional occupational identities. It is possible that the variance in occupationally based identifications revealed in the interviews was the result of more than one factor. Whether the actual cause is a difference in socialization, a stratification of acceptance within the firehouse, or a combination of factors remains unclear. However, what this research does indicate is that there are differing levels of identification within the occupation of firefighting that appears to be drawn largely along lines of gender.

The hypothesis of this study was that women would be unable to fully assimilate to the masculinized culture of firefighting. However, the research conducted to test this assumption does not reliably support the validity of this statement. Women have assimilated into the culture of firefighting. While the cultural expression of this community has changed, there does exist a culture of firefighting that is both accepting and open to female firefighters. This does not mean that the female firefighters in this study have adopted the group specific values of the occupations dominant group. The Fire Service, in response to the needs of the society that has created it, has undergone a period of redefinition and change. The result has been a broadening of categorizations, a reclassification of membership, and a variance in the level of identification with traditional occupationally based identities. 


\section{BIBLIOGRAPHY}

Ahrne, Goran. (1994). Social Organizations: Interaction Inside, Outside, and between Organizations. London: Sage Publications.

Babbie, Earl. (1995). The Practice of Social Research. New York: Wadsworth Publishing Co.

Berger, Peter L. \& Thomas Luckmann. (1966). The Social Construction of Reality: A Treatise in the Sociology of Knowledge. New York: Anchor Books.

Bernard, H. Russell. (1995). Research Methods in Anthropology: Qualitative and Quantitative Approaches. Walnut Creek, CA: Alta Mira Press.

Bologh, Roslyn W. (1990). Love or Greatness: Max Weber and Masculine Thinking-A Feminist Inquiry. Boston, MA: Unwin Hyman.

Bordt, Rebecca L. (1997). The Structure of Women's Nonprofit Organizations. Bloomington, IN: Indiana University Press.

Bourdieu, Pierre. (1979). Distinction: A Social Critique of the Judgment of Taste. Cambridge, Massachusetts: Harvard University Press.

Brightmire, Susan. (1995) “Diversity”. Fire Engineering, January, pp. 117-118.

Cargill, Kathleen M. (1996). Waiting for the Big One. Duluth, MN: Beeskeeper Press.

Chetkovich, Carol. (1998). Real Heat: Gender and Race in the Urban Fire Service. New Jersey: Rutgers University Press.

Clayton, Bill. (1984) "Female Inmates Work as Wildland Firefighters." American Fire Journal October, pp. 45-46.

DeBeauvoir, Simone. (1952). The Second Sex. New York: Vintage Books. 
Dellinger, Kirsten \& Christine Williams. (1997) "Makeup at Work: Negotiating Appearance Rules in the Workplace”. Gender \& Society, 11(2):151-177.

Delsohn, Steve. (1996). Firefighters Talk About Their Lives. New York: Harper Collins.

Douglas, Mary. (1970). Natural Symbols. London: Barrie \& Jenkins Press.

Farrell, Beth Grube. (1994). Gender Integration of the FDNY Firefighting Force: An Organizational Case Study. Columbia University: Dissertation.

Federal Emergancy Management Administration. (1999) National Fire Data Center. June, www.nfdc.gov

Fields, Leslie Leyland. (1997). The Entangling Net: Alaska's Commercial Fishing Women Tell Their Lives. Chicago: University of Illinois Press.

Floren, Terese M. (1991) “I Think I'd like to be a Firefighter". WFS Quarterly 6(1), Winter, pp. 1-4.

Gallagher, Art Jr. \& Harland Padfield. (1980). The Dying Community. Albuquerque, NM: University of New Mexico Press.

Geertz, Clifford. (1971). Myth, Symbol and Culture. New York: W.W. Norton \& Company.

Giddens, Anthony. (1984). The Constitution of Society. Berkeley, CA: University of California Press.

Greenberg, Amy S. (1997). Cause for Alarm: The Volunteer Fire Department in the Nineteenth-Century City. Princeton, NJ: Princeton University Press.

Harlan, Anne \& Carol L Weiss. (1982) "Sex Differences in Factors Affecting Managerial Career Advancement". Women in the Workplace, edited by Phyllis Wallace. Boston, MA: Auburn House Publishing Co. 
Hochschild, Arlie Russell. (1983).The Managed Heart: The Commercialization of Human Feeling. Berkeley, CA: University of California Press.

Holzman, Robert S. (1956). The Romance of Firefighting. New York: Harper \& Brothers.

International City Management Association. (1984). Effective Supervisory Practices. Washington, DC: ICMA.

Johns, John H. (1984). Cohesion in the U.S. Military. Wasington, D.C. National Defense University Press.

Keen, Sam. (1991). Fire in the Belly: On Being a Man. New York: Bantam Books.

Kim, Seung-Kyung. (1997). Class Struggie or Family Struggle: The Lives of Women Factory Workers in South Korea. Cambridge, MA: Cambridge University Press.

Kimmel, Micheal. (1996). Manhood in America. New York: The Free Press.

Kubler-Ross, Elizabeth. (1969). On Death and Dying. New York: Macmillan Publishing.

Lehne, Gregory K. (1998). "Homophobia Among Men: Supporting and Defining the Male Role”. Men's Lives, edited by Michael Kimmel \& Michael Messner. Boston, MA: Allyn \& Bacon.

Malinowski, Bronislaw. (1944). A Scientific Theory of Culture. Chapel Hill, NC: University of North Carolina Press.

March, James G. \& Simon, Herbert A. (1961). "The theory of Organizational Equilibrium". A Sociological Reader on Complex Organizations, edited by Amitai Etzioni. New York: Holt, Rinehart \& Winston, Inc.

McQueen, Iris. (1990) "Females in fire operations: Nightmare or dreamscape for the 90's". The California Fire Service, April, pp.13-17. 
McQueen, Iris. (1990) "Blowing Smoke: An Assessment of Attitudes and Values Concerning Females in California Fire Agencies". California Fire Service, September, pp. $12-21$.

Mead, Margaret. (1949). Male and Female. New York: Quill, William Morrow.

Modell, Judith \& Hinshaw, John. (1994). "Male Work and MillWork: Memory and Gender in Homestead, Pennsylvania". Gender and Memory: International yearbook of Oral History and Life Stories, edited by Selma Leydesdorff, Luisa Passenini \& Paul Thompson. Oxford: Oxford University Press.

Novack, David R. \& Leslie Lazin Novack. (1997) "Gender Disparity in the Advanced Industrial Society: Female-Male Relations at a Recently Coeducated College". Human Organization 56(2), Summer, pp.245-252.

Ogburn, William F \& Meyer F Nimkoff. (1964). A Handbook of Sociology. London: Routledge \& Kegan Paul Ltd.

Savage, Mike and Anne Witz. (1992).Gender and Bureaucracy. Cambridge, MA: Blackwell Publishers.

Sullivan, Teresa A. (1990). "The Decline of Occupations: Redefining the Labor Force". Change in Societal Institutions, edited by Hallinan, Klein \& Glass. New York: Plenum Press.

Summers, Liz. (1995) "We're Here to Stay: Reflections of a Woman in the Fire Service". The Voice, June, pp.41-44.

Surber, Jere Paul. (1998). Culture and Critique: An Introduction to the Critical Discourses in Cultural Studies. Boulder, CO: Westview Press.

Theberge, Nancy. (1997). "It's Part of the Game': Physicality and the Production of Gender in Women's Hockey”. Gender \& Society 11 (1), February, pp.69-87. 
Thompson, Michael, Richard Ellis \& Richard Wildavsky. (1990). Cultural Theory. Boulder, CO: Westview Press.

Walker, Karen. (1998). "I'm Not Friends the Way She's Friends: Ideological and Behavioral Constructions of Masculinity in Men's Friendships". Men's Lives, edited by Michael Kimmel \& Michael Messner. Boston, MA: Allyn \& Bacon.

Weber, Max. (1984). "Bureaucracy". Critical Studies in Organization \& Bureaucracy, Second Edition, edited by Fischer \& Sirianni. Philadelphia, PA: Temple University Press.

Williams, Christine. (1995). Still a Man's World. Berkeley, CA: University of California Press.

Winkle, William \& Raymond Navarre. (1985) "Females in the Fire Service: The Process of Acceptance". Fire Chief, April, pp.68-69.

"Women's Training Program Upgrades Firefighting Skills". (1991). Fire Chief, February, pp.60-61.

Yoder, Janice D. \& Patricia Aniakudo. (1996). "When Pranks Become Harassment: The Case of African-American Women Firefighters". Sex Roles 35(6), pp.253-269.

(1997). "Outsider Within' the Firehouse": Subordination and Difference in the Social Interactions of African American Women Firefighters". Gender \& Society 11(3), pp.324-341.

Zurier, Rebecca. (1982). The American Firehouse: An Architectural and Social History. New York: Abbeville Press. 


\section{APPENDIX 1}

\section{Interview Volunteers}

FFF1- Female, 38, White, Lieutenant, 15 years experience

FFF2- Female, 34, White, Paramedic, 8 years experience

FFF3- Female, 39, White, Paramedic, 9 years experience

FFF4- Female, 32, White, FF/E.M.T., 1 year experience

FFF5- Female, 39, White, Chief, 10 years experience

FFF6- Female, 29, White, FF/E.M.T., 5 years experience

FFF7- Female, 39, White, Paramedic, 18 years experience

FFF8- Female, 36, White, Special Assistant, 8 Years exp.

FFF9- Female, 36, White, FF/E.M.T., 7 years experience

FFF10- Female, White, Paramedic, 8 years experience

FFF11- Female, 32, White, Paramedic, 12 years experience

FFF12- Female, 30, White, Paramedic, 5 years experience

FFF13- Female, 30, African-American, Driver/Engineer, 5 years experience

MFF1- Male, 44, White, Paramedic/Driver, 28 years experience

MFF2- Male, 43, White, Chief, 27 years experience

MFF3- Male, 44, White, Lieutenant, 28 years experience

MFF4- Male, 32, White, FF/E.M.T., 1 year experience

MFF5- Male, 34, African-American, Paramedic, 6 years exp.

MFF6- Male, 33, White, Paramedic, 2 years experience

MFF7- Male, 37, White, Lieutenant, 17 years experience

MFF8- Male, 28, White, Paramedic, 5 years experience 
MFF9- Male, 34, African-American, FF/E.M.T., 5 Years exp.

MFF10- Male, 43, White, FF/E.M.T., 7 years experience

MFF11- Male, 32, White, Paramedic, 12 years experience

MFF12- Male, 41, White, FF/E.M.T., 20 years experience

MFF13- Male, White, Chief

MFF14- Male, African-American, Administrative Assistant II 


\section{APPENDIX 2}

Sample Interview Guide

\section{$\underline{\text { Personal }}$}

-Age

$-\operatorname{Sex}$

-Current Rank/Position

-Number of Years on the job

-Previous work in related fields

-Parental job classifications

-Reasons for selecting the FS as a career

-Values associated with firefighting

-What does it mean to be a FF

Professional

-Expectations of work prior to employment

-Training academy experiences

-Observable differences in performance expectations

-First duty contact with coworkers

-Importance of physical strength

-Importance of "family"

-Is the "family" atmosphere still present

-What has impacted cohesion among coworkers

-Rescue more appropriate for women 
-Nature of relationships with other firefighters

-What qualities make an individual a good $\mathrm{FF}$

-What is the relationship between individual and FS

-Are female firefighters expected to adapt

-Are male firefighters expected to adapt

-Are gender differences observed

-Should anyone be allowed to work in the FS

-What factor has had the most profound impact on your career

Expectations

-Aspect of FS most liked

-Aspect of FS least liked

-Overall job satisfaction

-Greatest change observed in the FS

-Greatest challenge facing the FS

-Future goals

-Individual concerns

-Suggestions for improvement 


\section{APPENDIX 3}

\section{Research Complications}

The main obstacle facing this research project was access to a sufficiently large sample population. By nature a bureaucracy, the Fire Service is riddled with procedures and levels of authority that must be maneuvered in order to gain access to the target group. Unfortunately, even the successful completion of this task does not guarantee either full access or complete participation.

In recent years, the Fire Service, like other government agencies, has come under increasing scrutiny that has been the result of past discriminatory practices. It is my belief that this increased social and political awareness, coupled with a fear of potential retribution has severely limited the researcher's ability to collect a great deal of meaningful data.

During the conduction of interviews for this research project, I could not help but notice a trend among the participants to avoid lengthy discussions that concerned potentially controversial subject matter. Whether the lack of participation was the result of concern about the group's perception of my research motivations or a lack of interest from the participants is unclear. What remains evident however, is the sensitivity to the subject matter among those who were willing to participate.

With this inhibiting factor in mind, any further research involving the firefighting community should involve a research population sufficiently large to overcome the overall lack of member participation. 